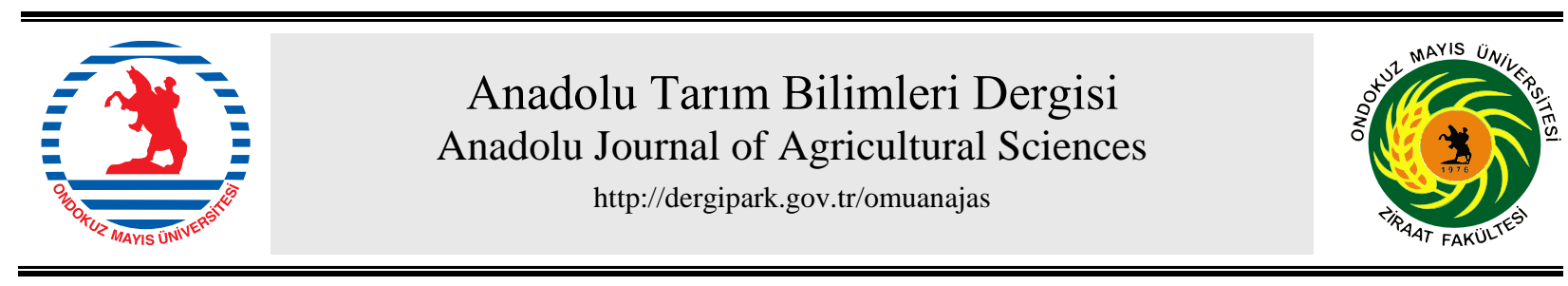

Araştırma/Research

Anadolu Tarım Bilim. Derg./Anadolu J Agr Sci, 36 (2021)

ISSN: 1308-8750 (Print) 1308-8769 (Online)

doi: 10.7161/omuanajas.737283

\title{
Hıyarda Bazı Bitki Gelişim Düzenleyici Kalıntılarının QuEChERS Analiz Yöntemi ile Metot Validasyonu
}

\author{
๑Tarık Balkan ${ }^{\mathrm{a}^{*}}$, ๑Kenan Kara ${ }^{\mathrm{a}}$ \\ ${ }^{a}$ Tokat Gaziosmanpaşa Üniversitesi, Ziraat Fakültesi, Bitki Koruma Bölümü, Tokat, Türkiye
}

*Sorumlu yazar/corresponding author: tarik.balkan@gop.edu.tr

Geliş/Received 14/05/2020～Kabul/Accepted 25/12/2020

\begin{abstract}
ÖZET
Bitki büyüme düzenleyicisi (BGD) olan absisik asit, giberallik asit ve paklobutrazol kalıntılarının belirlenmesi için QuEChERS yöntemi ile LC-MS/MS kullanılarak metot validasyonu gerçekleştirilmiştir. Metodun uygunluğu; tespit ve ölçüm limiti, doğrusallık ve doğruluk (tekrarlanabilirlik tekrarüretilebilirlik, geri alım) limitlerine göre değerlendirilmiştir. Matris etkisini ortadan kaldırmak için matrisli kalibrasyon kullanılmış, üç bitki gelişim düzenleyicisi için 10-200 $\mu \mathrm{g}$ $\mathrm{mL}^{-1}$ aralığında doğrusal sonuçlar ürettiği belirlenmiştir. Tüm BGD'ler için korelasyon katsayıları $\left(\mathrm{r}^{2}\right)$ 0.999 'dan büyük olduğu bulunmuştur. Tespit limitleri (LOD) 1.31 ve $1.70 \mu \mathrm{g} \mathrm{mL}^{-1}$, ölçüm limitleri (LOQ) 4.38 ve $5.68 \mu \mathrm{g} \mathrm{mL}^{-1}$ arasında değişkenlik göstermiştir. Geri alım çalışmaları için hıyar numuneleri absisik asit, giberallik asit ve paklobutrazol ile üç farklı konsantrasyon $(10,50$ ve $100 \mu \mathrm{g}$ $\mathrm{mL}^{-1}$ ) seviyesinde zenginleştirilmiştir. Tekrarlanabilirlik için, relatif standart sapma (RSD\%) 1.66 ile 11.61 arasında ve tekrarüretilebilirlik için (RSD\%), 3.40 ile 9.78 arasında bulunmuştur. Tüm metodun geri alımı \%105.41, RSD ise \%6.60 olarak bulunmuştur $(\mathrm{n}=540)$. Tüm veriler SANTE/11813/2017'de belirtilen geri alım sınırlarına (\%70-120) ve kesinlik kabul oranı için belirtilen değerlere (\%RSD $\leq$ \%20) uygundur.
\end{abstract}

Validation of QuEChERS method for the determination of some plant grow regulator residues in cucumber

\section{ABSTRACT}

Method validation was performed by QuEChERS method to determine the plant growth regulators abscisic acid, giberallic acid and paclobutrazole residues using LC-MS/MS. The method was validated according to limit of detection (LOD), limits of quantification (LOQ), linearity, accuracy and recovery. Calibration with matrix was used to elimination matrix effect. The linearity of three PGR were determined with the range of $10-200 \mu \mathrm{g} \mathrm{mL}^{-1}$. All correlation coefficients $\left(\mathrm{r}^{2}\right)$ were greater than 0.999 . The LODs were between 1.31 and $1.70 \mu \mathrm{g} \mathrm{mL}^{-1}$. The limits of quantification (LOQ) varied between 4.38 and $5,68 \mu \mathrm{g} \mathrm{mL}^{-1}$. The recovery of fortified cucumber samples in abscisic acid, gibberallic acid and paclobutrazole at three different concentrations $\left(10,50\right.$ ve $\left.100 \mu \mathrm{g} \mathrm{mL}^{-1}\right)$ were conducted. For repeatability, the relative standard deviation (RSD\%) ranged from 1.66 to 11.61, and for reproducibility, RSD\% ranged from 3.40 to 9.78 . The overall recovery of the method was $105.41 \%$ and the RSD was $6.60 \%(n=540)$. All results were compatible with the values specified in SANTE/11813/2017 for recovery $(70-120 \%)$ and repeatability (RSD $\% \leq 20 \%)$.

Anahtar Sözcükler:

Absisik asit

Giberallik asit Metot geçerliliği

Paklobutrazol

LC-MS/MS
Keywords: Abscisic acid Gibberallic acid Method validation Paclobutrazole LC-MS/MS

(c) OMU ANAJAS 2021 


\section{Giriş}

Bitki gelişim düzenleyiciler (BGD) genellikle düşük konsantrasyonlarda bitkilerin fizyolojik süreçlerini etkileyen besinler dışındaki organik bileşikler olarak tanımlanır. (Nickell, 1979). Sentetik olarak da üretilebilen BGD'ler genellikle oksin, giberellin, sitokinin, absisik asit, etilen, epibrassinolid, vb. gibi farklı kategorilere ayrılır (Pan ve ark., 2008). Oksinler, sitokininler ve gibberellinler bitkilerde büyüme uyarıcı, dorminler (ABA) ise engelleyici hormonlar olarak nitelendirilirler (Fırat, 1998; Walsh, 2003; Akgül, 2008; Kumlay ve Eryiğit, 2011). Bitki büyüme düzenleyicisi olarak yoğun bir şekilde kullanılan paklobutrazol ise bitkilerde büyümeyi geciktiri etkiye sahiptir. Paklobutrazol, gibberellin biyosentezini inhibe ederek, hücre uzaması ve sürgün büyümesinin azalmasını sağlamaktadır. Bu madde çiçeklenmenin kontrol edilmesinde, meyve türlerinde ürün ve kalitenin arttırılmasında kullanılmaktadır (Adato, 1990; Koukourikou-Petridou, 1996; Nartvaranant ve ark., 2000).

BGD’ler çelikle çoğaltmayı sağlamak, çimlenme gücünü artırmak, çiçeklenmeyi teşvik etmek veya geciktirmek, soğuğa dayanıklılığı artırmak, meyvelerde tohum oluşumunu ve meyve iriliğini artırmak, meyve muhafaza süresini uzatarak ihracat şansını arttırılar. Bunlara ilaveten bitkilerin hastalık ve zararlılara dayanıklılığını artırmak, yabancı ot kontrolünü sağlamak, pamuk ve tahıllarda yatmayı önlemek, hasat öncesi meyve dökülmesine engel olmak, makinalı hasadı kolaylaştırmak için tüm bitkilerin aynı zamanda olgunlaşmasını sağlamak, patateste dormansiyi kırmak, özellikle doku kültürü çalışmalarında kök-sürgün ve yumru oluşumunu teşvik etmek gibi vazifelere de sahiptirler (Budak ve ark., 1994; Kaynak ve Ersoy, 1997). Tarımsal üretimde söz sahibi olmak isteyen ülkeler, pestisitler yanında BGD'leri de yoğun olarak kullanmaktadırlar. Bunların yarılanma ömürleri uzun olup, toprakta, sebze ve meyveler üzerinde kalmaktadır. Kontrolsüz ve bilinçsiz bir şekilde aşırı miktarlarda kullanımı ile ürünlerde oluşan kalıntı, insan ve çevre sağlı̆̆ı üzerinde endişelere neden olmaktadır.

Yapılan araştırmalarda BGD'lerin memelilerde fertiliteyi ve mast hücrelerinin (Bağışıklık sisteminde önemli rolleri olan ve özellikle alerji ve anafilaksideki yeriyle tanınan hücreler) yoğunluğunu arttırarak Substance P (SP) düzeyini (ağr iletiminden sorumlu olan maddeler) etkiledikleri (Sorensen ve Danielsen, 2006; Erin ve ark., 2008), canlı sistemden tamamen atılamayıp organlarda depolandıkları, fonksiyon bozukluklarına ve üretilen serbest radikallere karşı vücudun kendisinin savunma direncinin azalmasına neden oldukları ifade edilmektedir (Yılmaz ve Yüksel, 2002a; Yılmaz ve Yüksel, 2002b; Pektaş, 2009; Yılmaz ve ark, 2014). Dünyada BGD’ler, ruhsat ve denetim, ayrıca çevre ve sağlık açısından, pestisitler içerisinde bir alt grup olarak işlem görmektedir (Anonim, 2020a). Bu yüzden Japonya, Tayvan, Çin, Avrupa Birliği ve Amerika Birleşik Devletleri gibi ülkelerin, pestisit kalıntıları için oluşturmuş olduğu ulusal ve uluslararası kuruluşlar, tarımsal ürünlerdeki BGD kalıntı miktarlarını düzenlemek ve izleyebilmek için MRL (Maksimum Kalıntı Limitleri) geliştirmektedirler (Pu ve ark., 2018). Ülkemizde ise Türk Gıda Kodeksi Pestisitlerin Maksimum Kalıntı Limitleri Yönetmeliğinde (TGK-PKY), Absisik asit (ABA), Giberallik asit $\left(\mathrm{GA}_{3}\right)$ ve Paklobutrazol (PBZ) ile ilgili henüz MRL değerleri mevcut değildir.

Bununla birlikte, BGD kalıntılarının belirlenmesi, eser konsantrasyonları nedeniyle hala oldukça zor olup tespitinde uygun ve hızlı analitik yöntemler gereklidir. Bitkilerdeki BGD kalıntı seviyelerini saptamak için farklı yöntemler tanımlanmıştır. Şimdiye kadar, enzime bağlı immünosorban deneyi (ELISA), gaz kromatografisi (GC), sıvı kromatografisi (LC), gaz kromatografisi kütle spektrometrisi (GC-MS), sıvı kromatografisi kütle spektrometrisi (LC-MS) ve kılcal elektroforez (CE) dahil olmak üzere bitki büyüme düzenleyicilerini ölçmek için bir dizi yöntem geliştirilmiş̧ir (Brinkman ve ark., 1996; Liu ve ark., 2002; Hu ve Li, 2006; Amer ve ark., 2007; Li ve Tian, 2007; Valverde ve ark., 2007; Chen va ark., 2010; Pantaleón ve ark., 2010; Han ve ark., 2012; Wu ve ark., 2014; ) Bu yöntemler arasında hızlı ve güvenilir sonuç vermesi nedeniyle LC-MS' in QuEChERS yöntemi ile birlikte kullanımı son yıllarda yaygınlaşmışıır (López-Carbonell ve ark., 2009; Zhang ve ark., 2012). Son yıllarda dünyada BGD’lerle ilgili çalışmalar konunun ehemmiyeti nedeniyle giderek artış eylemi göstermektedir. Aşağıdaki araştırıcılar metot validasyonuyla ilgili farklı çalışmalar gerçekleştirmişlerdir. Yan ve ark. (2016), meyvelerde paklobutrazol ve giberallik asit' in içlerinde olduğu altı BGD ile yaptıkları çalışmada korelasyon katsayısını 0.999 üzerinde, geri alımı değerlerini \%60,77-119,43 (\%RSD 0,18-32,94) arasında bulmuşlardır. Üzümde 24 bitki gelişim düzenleyicisini belirlemek üzere QuEChERS metodunu modifiye ederek yaptıkları çalışmada korelasyon katsayısını 0.995 üzerinde, geri alım değerlerini \%70.12-112.6, tekrar edebilirlik değerlerini ise \%67.05-101.8 arasında saptamışlardır. Liu ve ark. (2017), Çin'de 19 bitki gelişim düzenleyicisi üzerinde korelasyon katsayısını 0.997 üzerinde, geri alımı değerlerini \%72.3-115.8 (\%RSD 1.78-5.32) arasında tespit etmişlerdir. Yaptıkları çalışmada süpermarketlerden aldıkları 280 bitki numunesinden 12' sinde BGD kalıntısı tespit etmişlerdir.

Hıyarlarda da pestisit kalıntılarının araştırılması için yapılan bir metot geçerliliği çalışmasında LC-MS/MS kullanılmış çalışma sonuçlarına göre korelasyon katsayısı 0.999 üzerinde, geri alım değerleri \%74,70-114,09 arasında, tüm metod geri alımını ise \%94 olarak saptamışlardır (Çatak ve Tiryaki, 2019).

TGK-Pestisitlerin Maksimum Kalıntı Limitleri Yönetmeliğinde çalışılan maddelerin MRL kalıntı limitlerinin mevcut olmaması gıda güvenliği açısından sakıncalar oluşturmaktadır. Bu bağlamda hızlı ve güvenilir bir yöntem 
olan QuEChERS metodu LC-MS/MS ile birlikte valide edilerek absisik asit, giberallik asit ve paklobutrazol'ün gıdalardaki kalıntı miktarlarının tespiti amaçlanmıştır.

\section{Materyal ve Yöntem}

\subsection{Kimyasallar}

Bitki gelişim düzenleyici referans standartları Absisik asit (ABA) ve Giberallic asit $\left(\mathrm{GA}_{3}\right)$ supelco analytical'dan (Bellefonte, PA, ABD), Paklobutrazol (PBZ) Dr. Ehrenstorfer'dan (Augsburg, Almanya) temin edilmiş olup mezkur maddelerin kimyasal yapıları Şekil 1'de gösterilmiştir. Asetonitril (MeCN), metanol $(\mathrm{MeOH})$, Magnezyum sülfat susuz $\left(\mathrm{MgSO}_{4}\right)$, sodyum asetat (NaOAc), formik asit (FA) ve asetik asit ( $\left.\mathrm{AcOH}\right)$ Merck'ten (Darmstadt, Almanya) temin edilmiştir. Her bir BGD'nin stok standart çözeltileri $1000 \mu \mathrm{g} \mathrm{mL} \mathrm{L}^{-1}$ olacak şekilde $12 \mathrm{ml}$ 'lik vida kapaklı cam tüplerde hazırlanmıştır. Hazırlanan solvent $-20^{\circ} \mathrm{C}$ 'de muhafaza edilmiş, standart çözeltilerinin hazırlanması için HPLC saflığında asetonitril ve metanol kullanılmıştır.

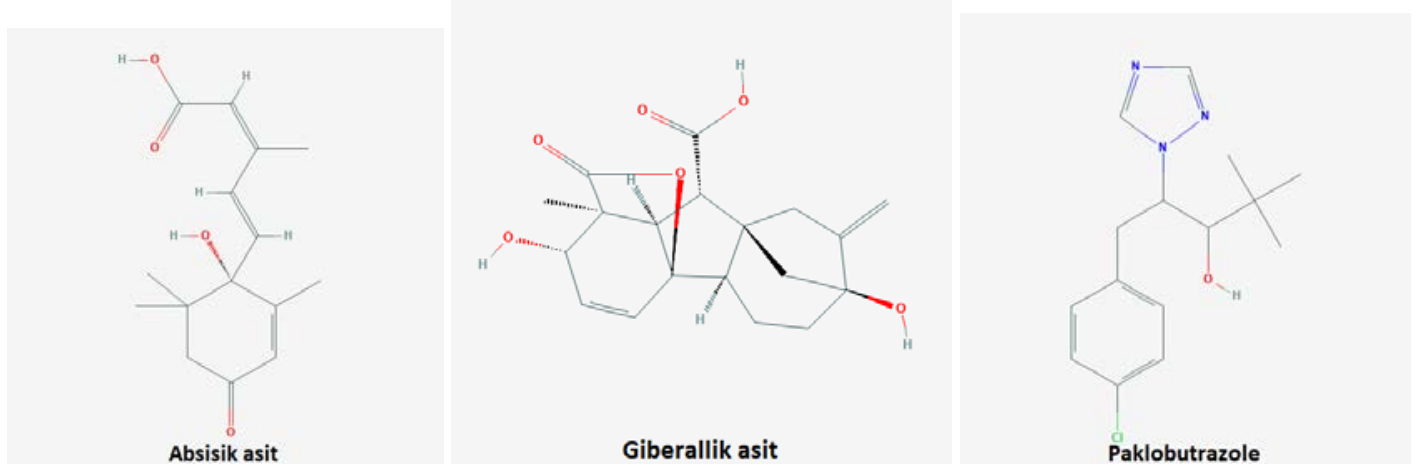

Şekil 1. Absisik asit, giberallik asit ve paclobutrazol' ün kimyasal yapıları (Anonim, 2020b)

Figure 1. Chemical structures of abscisic acid, gibberallic acid and paclobutrazole

\subsection{Cihaz ve gereçler}

Kromatografik analizler için LC-MS/MS (Quadrupole Schimadzu LC-MS/MS-8050) kullanılmıştır. Ekstraksiyonda Santrifüj (Hettich Rotina 380, 50 ml'lik ve Hettich Universal 320R, 15 ml'lik santrifüj tüpüne uygun), hassas terazi (Shimadzu AUW220D, $\pm 0.0001 \mathrm{~g}$ ), sanayi tipi öğütücü (Empero), Vortex (Ika) kullanılmıştır. Ayrıca mikropipet, şırınga, $50 \mathrm{ml}$ 'lik falkon tüpleri, piset, ultrasonik banyo, 2 ve 12 ml'lik vida kapaklı cam vialler, 5 ml'lik şırıngalar, 45/25 mm'lik şırınga filtreleri, balon joje, tek kullanımlık pipet ve tartım kapları gibi çeşitli malzemeler analizlerde kullanılmıştır.

\subsection{Fortifikasyon işlemi}

Homojenize edilmiş hıyar örneklerinin absisik asit, giberallik asit ve paklobutrazol ile zenginleştirilmesi (fortifikasyon) 3 farklı düzeyde BGD standart solüsyonu ile 5 tekrarlı olarak gerçekleştirilmiştir (Çizelge 1).

Çizelge 1. Hıyar örneklerinin fortifikasyon düzeyleri

Table 1. Fortification levels of cucumber samples

\begin{tabular}{lccc}
\hline Fortifikasyon seviyesi & Absisik asit $\left(\mu \mathrm{g} \mathrm{kg}{ }^{-1}\right)$ & Giberallik asit $\left(\mu \mathrm{g} \mathrm{kg}{ }^{-1}\right)$ & Paklobutrazol $\left(\mu \mathrm{g} \mathrm{kg}^{-1}\right)$ \\
\hline Seviye 1 & 10 & 10 & 10 \\
Seviye 2 & 50 & 50 & 50 \\
Seviye 3 & 100 & 100 & 100 \\
Kontrol & - & - & - \\
EU-MRL & - & - & 10 \\
\hline
\end{tabular}




\section{4 Örneklerin ektraksiyonu ve clean up}

Ekstraksiyon ve clean up prosedürleri resmi AOAC Metodu 2007.01 kullanılarak gerçekleştirilmiştir (Leho tay, 2007). Numuneler (yaklaşık $1 \mathrm{~kg}$ ) (EC, 2002) çelik bir öğütücüde homojenize edilmiştir. Homojenize edilen hıyar numunesi (analitik kısım) $15 \mathrm{~g}$ tartılarak $50 \mathrm{~mL}$ santrifüj tüplerine konulmuş üzerine $15 \mathrm{ml} \% 1$ asetik asit $(\mathrm{AcOH})$ içeren asetonitril $(\mathrm{MeCN})$ eklenmiş devamında Şekil 2'de gösterilen protokol takip edilmiştir. Her analitik porsiyondan 3 GC viyaline örnek alınarak LC-MS/MS'de analiz edilmiştir (Polat ve Tiryaki, 2019).

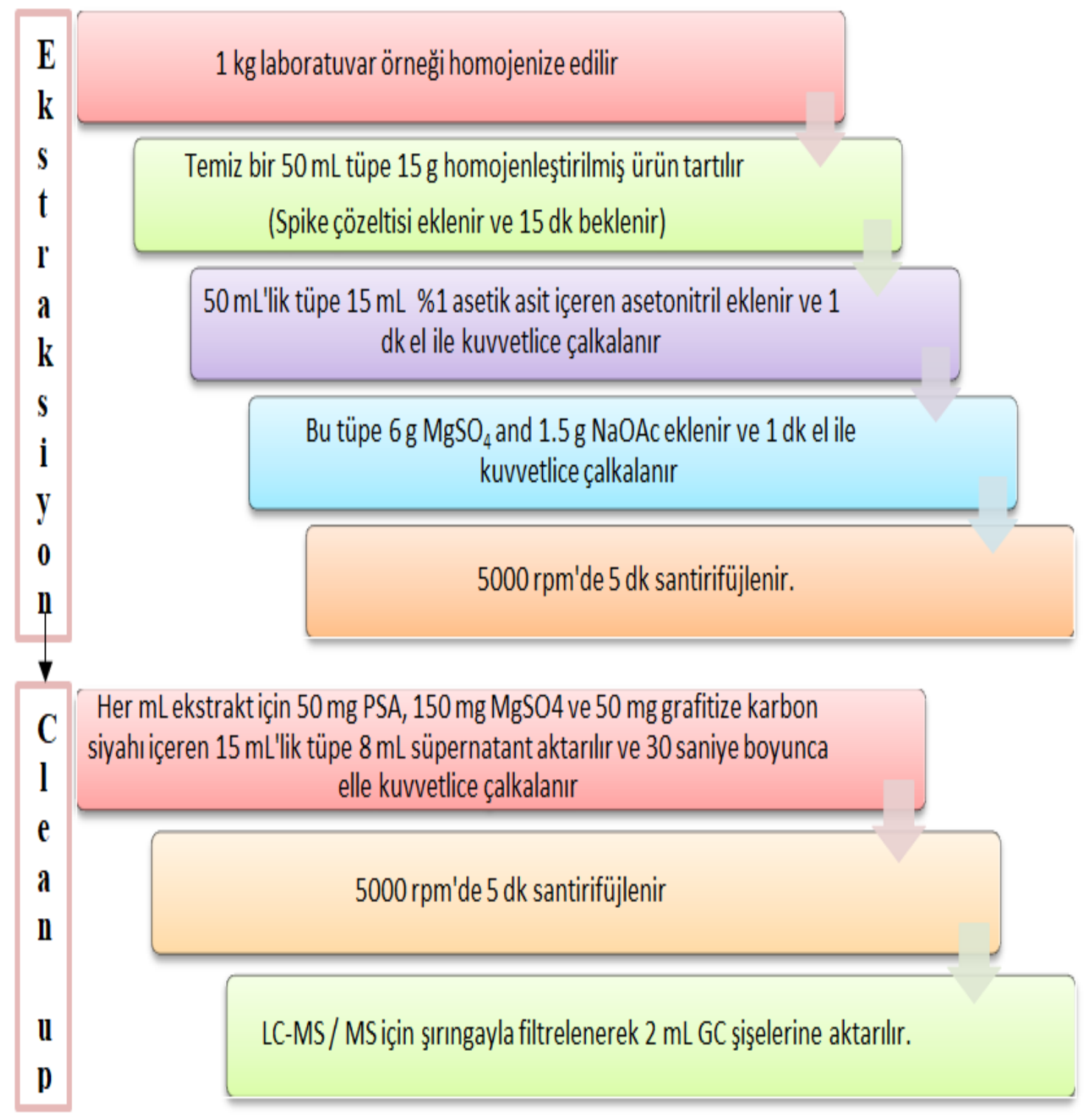

Şekil 2. QuEChERS-AOAC Resmi Metodu 2007.01'nun analitik basamakları

Figure 2. Analytical protocol of the QuEChERS-AOAC Official Method 2007.01

\subsection{Kromatografik koşullar}

Kromatografik analizler Tokat Gaziosmanpaşa Üniversitesi Bilimsel ve Teknolojik Araştırmalar Uygulama ve Araştırma Merkezi Gıda Tespiti ve Kalıntı Analiz Birimi’nin Gıda Kalıntı Analiz Laboratuvarındaki LC-MS/MS (Sıvı Kromatografi/ Tandem Kütle Spektrometresi) cihazı kullanılarak yapılmıştır. Cihazın çalışma koşulları Çizelge 2'de verilmiştir. 
Çizelge 2. Kromatografik koşullar

Table 2. Chromatographic conditions

\begin{tabular}{|c|c|c|c|}
\hline LC-MS/MS cihazı & \multicolumn{3}{|c|}{ Shimadzu 8050} \\
\hline Mobil Faz A & \multicolumn{3}{|c|}{ Metanol+distile su+formik asit (99:900:1) } \\
\hline Mobil Faz B & \multicolumn{3}{|c|}{ Metanol+distile su+formik asit (900:99:1) } \\
\hline Mobil Faz Akış & \multicolumn{3}{|c|}{$0.3 \mathrm{ml} / \mathrm{dk}$} \\
\hline Kolon & \multicolumn{3}{|c|}{ C18 Inertsil ODS- $4 ; 3 \mu \mathrm{m} ; 2.1 \times 150 \mathrm{~mm}$} \\
\hline \multirow[t]{6}{*}{ Gradiyent program } & Zaman (dk) & $\% A$ & $\% \mathrm{~B}$ \\
\hline & $0-1$ & 98 & 2 \\
\hline & $1.01-8$ & 5 & 95 \\
\hline & $8.01-12$ & 5 & 95 \\
\hline & $12.01-13$ & 98 & 2 \\
\hline & $13.01-18$ & 98 & 2 \\
\hline Kolon (Fırın) sıcaklığı & $35^{\circ} \mathrm{C}$ & & \\
\hline Enjeksiyon Hacmi & $10 \mu \mathrm{L}$ & & \\
\hline MS Gaz Sicaklığı & $300^{\circ} \mathrm{C}$ & & \\
\hline MS Gaz Akışı & $10 \mathrm{~L} / \mathrm{dk}$ & & \\
\hline Nebulizatör Basıncı & $270 \mathrm{kPa}$ & & \\
\hline Oda sıcaklığı & $20^{\circ} \mathrm{C} \pm 1$ & & \\
\hline
\end{tabular}

\section{Bulgular ve Tartışma}

Üç bitki gelişim düzenleyicinin MS/MS parametrelerini elde etmek için, stok standart çözeltilerinden metanol ile hazırlanan $1000 \mu \mathrm{g} \mathrm{mL}^{-1}$ 'lik çözeltiler kütle spektrometresine $0.3 \mathrm{ml} / \mathrm{dk}$ akış hızında verildi ve MS/MS parametreleri belirlendi (Çizelge 3). Optimum hassasiyet paclobutrazol için pozitif iyon modunda, absisik asit ve giberallik asit için negatif iyon modunda elde edilmiştir. Metot validasyonu tek laboratuvar validasyon yaklaşımına göre valide edilmiştir (EUROCHEM, 2014). Yöntemin performansı doğrusallık, doğruluk, tespit limiti (LOD) ve ölçüm limiti (LOQ) kriterleri ile belirlenmiştir.

Çizelge 3. Absisik asit, giberallik asit ve paklobutrazol’ ün ana iyon kütleleri, ürün iyon kütleleri ve çarpışma enerjileri

Table 3. Precursor ion $(\mathrm{m} / \mathrm{z})$, product ion $(\mathrm{m} / \mathrm{z})$ and collision energies of abscisic acid, gibberallic acid and paclobutrazole

\begin{tabular}{cccc}
\hline BGD & $\begin{array}{c}\text { Ana İyon Kütlesi } \\
(\mathrm{g} / \mathrm{mol})\end{array}$ & $\begin{array}{c}\text { Ürün İyon Kütleleri } \\
(\mathrm{g} / \mathrm{mol})\end{array}$ & Çarpışma Enerjisi (eV) \\
& 263.10 & $122.00 / 188.10 / 203.20$ & $34.0 / 37.0 / 28.0$ \\
Absisik asit & 345.00 & $143.10 / 221.30$ & $28.0 / 26.0$ \\
Giberallik asit & 294.20 & $125.00 / 165.00$ & $-38.0 /-23.0$ \\
Paklobutrazol & &
\end{tabular}

Üç bitki gelişimi düzenleyici madde için kalibrasyon noktaları, son konsantrasyon 10, 25, 50, 100 ve 200 $\mu \mathrm{g} \mathrm{mL}{ }^{-1}$ olacak şekilde matriks uyumlu olarak hazırlanmıştır. Her bir kalibrasyon noktası 3 tekrarlı enjeksiyon ile elde edilmiştir. Çalışılan tüm BGD’lerin kalibrasyonlarına ait korelasyon katsayıları $\left(\mathrm{r}^{2}\right) 0.999$ değerinin üzerinde tespit edilmiştir (Çizelge 4). Bu sonuç, oluşturulan programın geniş bir konsantrasyon aralığında doğrusal olduğunu göstermektedir. Absisik asit, giberallik asit ve paklobutrazol 'ün kromatogramları ve kalibrasyon grafikleri Şekil 3 'de verilmiştir. 
Çizelge 4. Kalibrasyon eğrilerine ait korelasyon kat sayıları

Table 4. Correlation coefficients of calibration curves

\begin{tabular}{ccc}
\hline BGD & Korelasyon Katsayısı $\left(\mathrm{r}^{2}\right)$ & Kalibrasyon eğrisi \\
\hline Absisik asit & 0.9995403 & $\mathrm{Y}=153.288 \mathrm{X}+14538,1$ \\
Giberallik asit & 0.9996081 & $\mathrm{Y}=549.958 \mathrm{X}+1308,77$ \\
Paklobutrazol & 0.9998127 & $\mathrm{Y}=4708.31 \mathrm{X}+1004640$ \\
\hline
\end{tabular}
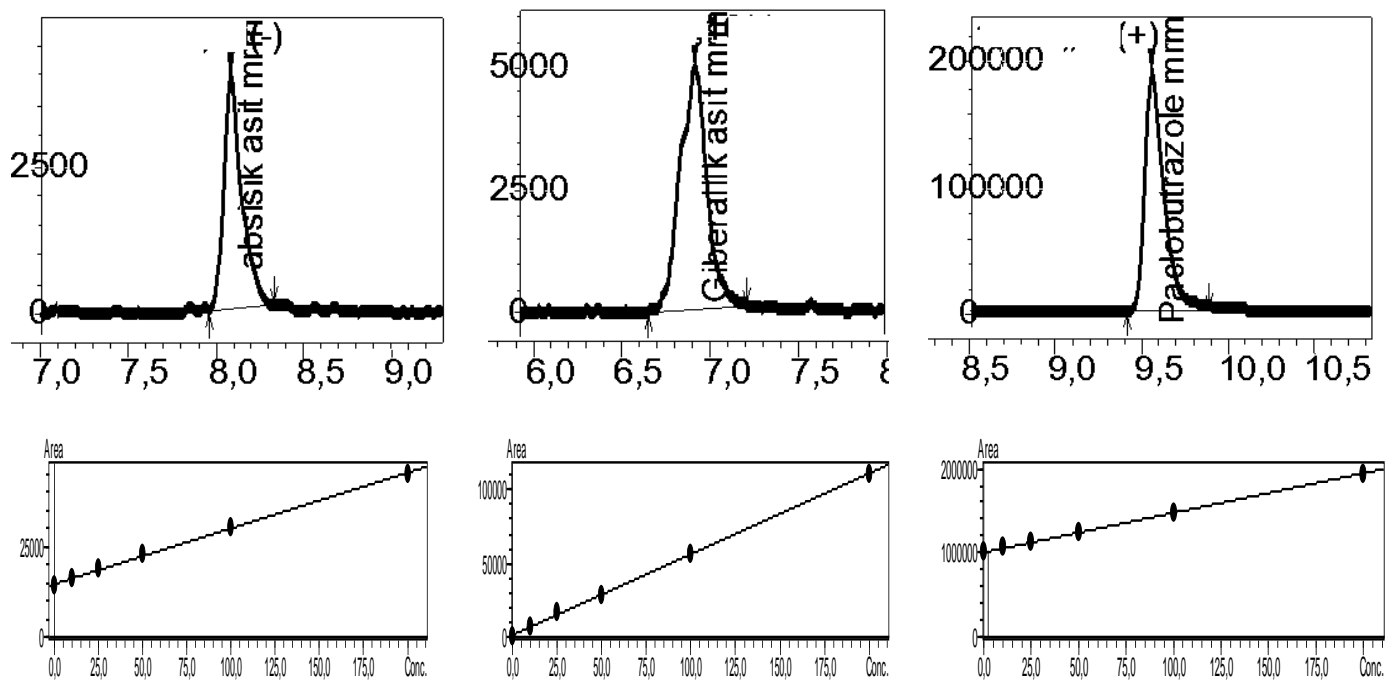

Şekil 3. Matriks uyumlu standartların kromatogramları $\left(100 \mu \mathrm{g} \mathrm{mL}^{-1}\right)$ ve kalibrasyon eğrileri Figure 3. Chromatogram of matrix-matched standards $\left(100 \mu \mathrm{g} \mathrm{mL}^{-1}\right)$ and calibration curves

\subsection{Geri alım testleri}

QuEChERS yöntemi gelişmiş laboratuvarlarda yaygın kullanımına rağmen kendi laboratuvar koşullarımız için doğrulanmasına hala ihtiyaç vardır (Çatak ve Tiryaki, 2020). Bu amaçla homojenize edilen hıyar numunesi (analitik kısım) $15 \mathrm{~g}$ tartılarak $50 \mathrm{~mL}$ 'lik santrifüj tüplerine konulmuş üzerine $75 \mu \mathrm{L}$ BGD (MeCN) çözeltisi eklenerek 10, 50 ve $100 \mu \mathrm{g} \mathrm{mL}^{-1}$ fortifikasyon seviyeleri elde edilmiştir (Çizelge 1). 30 saniyelik vortekslemenin ardından numuneler, BGD’nin matris ile etkileşimi için 15 dakika bekletilmiştir (Şekil 2). Her analitik kısım, LC-MS/MS ile üç kez (3 GC viali) analiz edilmiştir (Polat ve Tiryaki, 2019).

\subsection{Doğruluk}

Doğruluk; gerçeklik (geri alım) ve kesinlik (tekrarlanabilirlik ve tekrarüretilebilirlik) parametrelerini kapsayan bir parametredir (SANCO, 2011). Tekrarlanabilirlik çalışması aynı günde 5 kez üç farklı fortifikasyon seviyesinde $\left(10,50\right.$ ve $\left.100 \mu \mathrm{g} \mathrm{mL}^{-1}\right)$ yapılmıştır. Metot kapsamındaki tüm bileşikler için, tekrarlanabilirlik geri alım değerleri \%95.2-114.5, \% RSD değerleri 1.66 ile 11.61 aralığında bulunmuştur (Çizelge 5). 
Çizelge 5. Tekrarlanabilirlik için; \% ortalama geri alım, standart sapma, \% relatif standart sapma (\%RSD) değerleri Table 5. For repeatability; \% Mean recovery, SD and RSD\%

\begin{tabular}{|c|c|c|c|c|c|c|c|c|c|c|}
\hline \multirow{3}{*}{ Analit } & \multicolumn{10}{|c|}{ Fortifikasyon seviyesi, $\mu \mathrm{g} \mathrm{mL}^{-1}$} \\
\hline & \multicolumn{4}{|c|}{10} & \multicolumn{3}{|c|}{50} & \multicolumn{3}{|c|}{100} \\
\hline & & $\begin{array}{l}6 \text { Ortalama } \\
\text { geri alım }\end{array}$ & SD & $\begin{array}{c}\text { RSD, } \\
\%\end{array}$ & $\begin{array}{l}\text { \% Ortalama } \\
\text { geri alım }\end{array}$ & SD & $\begin{array}{c}\text { RSD, } \\
\%\end{array}$ & $\begin{array}{l}\text { \% Ortalamé } \\
\text { geri alım }\end{array}$ & SD & $\begin{array}{c}\text { RSD, } \\
\%\end{array}$ \\
\hline Absisik asit & 1 & 102.4 & 0.76 & 7.44 & 107.9 & 4.15 & 7.69 & 104.7 & 5.09 & 4.86 \\
\hline $\mathrm{n}=90$ & 2 & 99.2 & 1.15 & 11.61 & 98.4 & 2.37 & 4.83 & 101.8 & 4.55 & 4.47 \\
\hline Giberallik asit & 1 & 114.5 & 0.25 & 2.14 & 100.3 & 0.83 & 1.66 & 110.2 & 4.92 & 4.47 \\
\hline $\mathrm{n}=90$ & 2 & 106.0 & 0.82 & 7.73 & 95.2 & 1.13 & 2.36 & 109.2 & 3.78 & 3.46 \\
\hline Paklobutrazol & 1 & 104.6 & 0.70 & 6.71 & 104.4 & 3.10 & 5.94 & 106.9 & 4.66 & 4.36 \\
\hline $\mathrm{n}=90$ & 2 & 105.6 & 1.03 & 9.79 & 106.5 & 2.52 & 4.72 & 108.2 & 4.74 & 4.39 \\
\hline
\end{tabular}

Tekrarüretilebilirlik çalışması beş farklı zamanda üç farklı fortifikasyon seviyesinde $\left(10,50\right.$ ve $\left.100 \mu \mathrm{g} \mathrm{mL} \mathrm{L}^{-1}\right)$ yapılmıştır. Metot kapsamındaki tüm bileşikler için, tekrarüretilebilirlik geri alım değerleri \%95.71-107.55 \%RSD değerleri 3.40 ile 9.78 aralı̆̆ında bulunmuştur (Çizelge 6). Tüm metodun geri alımı ise \%105,41 (RSD \%6,60) olarak bulunmuştur $(\mathrm{n}=540)$.

Çizelge 6. Tekrarüretilebilirlik için; \% ortalama geri alım, standart sapma, \% relatif standart sapma (\%RSD) değerleri

Table 6. For reproducibility \% Mean recovery, SD and RSD

\begin{tabular}{|c|c|c|c|c|c|c|c|c|c|}
\hline \multirow{4}{*}{ Analit } & \multicolumn{9}{|c|}{ Fortifikasyon seviyesi, $\mu \mathrm{g} \mathrm{mL}^{-1}$} \\
\hline & \multicolumn{3}{|c|}{10} & \multicolumn{3}{|c|}{50} & \multicolumn{3}{|c|}{100} \\
\hline & & & & & & & $\%$ & & \\
\hline & $\begin{array}{l}\% \text { Ortalama } \\
\text { geri alım }\end{array}$ & SD & $\begin{array}{c}\text { RSD, } \\
\%\end{array}$ & $\begin{array}{l}\text { \% Ortalama } \\
\text { geri alım }\end{array}$ & SD & $\begin{array}{c}\text { RSD, } \\
\%\end{array}$ & $\begin{array}{l}\text { Ortalama } \\
\text { geri alım }\end{array}$ & SD & $\begin{array}{c}\text { RSD, } \\
\%\end{array}$ \\
\hline $\begin{array}{c}\text { Absisik asit } \\
\text { n=90 }\end{array}$ & 101.16 & 0.78 & 7.48 & 103.29 & 4.11 & 7.96 & 105.70 & 4.29 & 4.06 \\
\hline $\begin{array}{c}\text { Giberallik asit } \\
\quad \mathrm{n}=90\end{array}$ & 106.96 & 1.05 & 9.78 & 95.71 & 1.63 & 3.40 & 107.55 & 7.63 & 7.09 \\
\hline $\begin{array}{c}\text { Paklobutrazol } \\
n=90\end{array}$ & 104.52 & 0.82 & 7.84 & 106.93 & 3.16 & 5.92 & 106.23 & 6.26 & 5.90 \\
\hline
\end{tabular}

\section{3. $L O D$ ve $L O Q$ değerleri}

Çalışmalar, tek konsantrasyonda $\left(10 \mu \mathrm{g} \mathrm{mL}^{-1}\right) 10$ tekrarlı olarak yapılmış ve her bir BGD'ye ait standart sapma (SD) ve bağıl standart sapma (\%RSD) değerleri hesaplanmıştır. Hesaplanan standart sapma değerlerinin 3 katı her bir bitki gelişim düzenleyicisi için LOD, 10 katı ise LOQ değeri olarak belirlenmiştir. Absisik asit için LOD ve LOQ değerleri, sırasıyla 1.42 ve 4.75 , giberallik asit için 1.70 ve 5.68 , paklobutrazol için ise 1.31 ve 4.38 olarak hesaplanmıştır (Çizelge 7). 
Çizelge 7. Ortalama, standart sapma, relatif standart sapma, LOD ve LOQ değerleri

Table 7. Mean, SD, RSD, LOD and LOQ, values

\begin{tabular}{cccc}
\hline & $\begin{array}{c}\text { Absisik asit } \\
\left(\mu \mathrm{g} \mathrm{mL}^{-1}\right)\end{array}$ & $\begin{array}{c}\text { Giberallik asit } \\
\left(\mu \mathrm{g} \mathrm{mL}^{-1}\right)\end{array}$ & $\begin{array}{c}\text { Paklobutrazol } \\
\left(\mu \mathrm{g} \mathrm{mL}^{-1}\right)\end{array}$ \\
\hline Ort. & 9.92 & 9.65 & 9.81 \\
SD & 0.47 & 0.57 & 0.44 \\
RSD,\% & 0.05 & 0.06 & 0.04 \\
LOD & 1.42 & 1.70 & 1.31 \\
LOQ & 4.75 & 5.68 & 4.38 \\
\hline
\end{tabular}

\section{Sonuç}

$\mathrm{Bu}$ çalışma, eşzamanlı olarak 3 bitki gelişim düzenleyicisinin yüksek su içerikli ürünlerde (hıyar, domates, elma, kayısı vb.) kalıntı miktarlarını belirlemek için analitik bir yöntem sunmaktadır. Kromatografik ayrım 9,754. dakikada sonlanmış, piklerin birbiri ile çakışmadan ayrıldığı ve ayrımın 3,5 dakika gibi kısa bir zamanda nihayete erdiği gözlemlenmiştir. Ancak kolonun yüksek sıcaklıkta temizlenmesi ve tekrar şartlanması için toplam analiz süresi uzatılarak 18 dakika olarak belirlenmiştir. Çalışma sonucunda elde edilen doğrusallık, doğruluk, kesinlik, LOD ve LOQ gibi metot validasyon parametreleri istenen geri alım aralığına (\%70-120) ve tekrarlanabilirlik şartı için belirtilen değerlere (RSD $\leq \% 20$ ) uygundur (SANTE, 2017). Bu çalışma yüksek su içerikli ürünlerde absisik asit, giberallik asit ve paklobutrazol'ün kalitatif ve kantitatif analizleri için laboratuvarımızda uygun bir metot sunmaktadır.

\section{Kaynaklar}

Adato, I., 1990. Effects of paclobutrazol on avocado (Persea americana Mill.) cv.'Fuerte’. Scientia Horticulturae, 45 (1-2): 105-115. doi:10.1016/0304-4238(90)90073-N

Akgül, H., 2008. Büyüme ve Gelişim Düzenleyiciler, Eğirdir Bahçe Kültürleri Araştırma Enstitüsü Yayını, Yayın No:12.

Amer, M.M., Shehata, M.A., Lotfy, H.M., Monir, H.H., 2007. Determination of Tetraconazole and Diniconazole Fungicide Residues in Tomatoes and Green Beans by Capillary Gas Chromatography. Yakugaku Zasshi, 127(6): 993. doi:10.1248/yakushi.127.993

Anonim, 2020a. http://www.zimid.org/sunumlar/toplum-sagligi-ve-hormonlu-gidalar.pdf (Erişim tarihi: 21 Şubat.2020).

Anonim, 2020b. https://pubchem.ncbi.nlm.nih.gov/compound/Paclobutrazol, https://pubchem.ncbi .nlm.ni.gov/compound/5280896, https://pubchem.ncbi.nlm.nih.gov/compound/6466 (Erişim tarihi: 13 Mayıs 2020).

Brinkman, J.H.W., Van Dijk, A.G., Wagenaar, R., Quirijns, J.K., 1996. Determination of daminozide residues in apples using gas chromatography with nitroge-phosporus detection. J Chromatogr. A, 723, 355. doi:10.1016/0021-9673(95)00845-4

Budak, N., Çalışkan, C.F., Çaylak, Ö., 1994. Bitki büyüme regülatörleri ve tarımsal üretimde kullanımı, Ege Üniv. Zir. Fak. Dergisi, 31: 289-296.

Chen, H., Zhang, Z.X., Zhang, G.M. Guo, X.F., Zhang, H.S., Wang, H., 2010. Liquid Chromatographic Determination of Endogenous Phytohormones in Vegetable Samples Based on Chemical Derivatization with 6Oxy(acetylpiperazine) Fluorescein. Journal of Agricultural and Food Chemistry 58 (8): 4560-4564. doi:10.1021/jf100581u

Çatak, H., Tiryaki, O. 2019. Validation of QuEChERS method for the analyses of acetamiprid, chlorpyrifos and formetanate hydrochloride residues in cucumbers. 1st International Erciyes Agriculture, Animal and Food Sciences Conference (AGANFOS-2019) (pp.375-378). Kayseri, Turkey

Çatak, H , Tiryaki, O. 2020. Insecticide residue analyses in cucumbers sampled from Çanakkale open markets . Turkish Journal of Entomology , 44 (4) , 449-460 . DOI: 10.16970/entoted.767482

Erin, N., Afacan, B., Ersoy, Y., Ercan, F., Balc1, M.K., 2008. Gibberellic acid, a plant growth regulator, increases mast cell recruitment and alters substance P levels. Toxicology;254(1-2):75-81. doi:10.1016/j.tox.2008.09.020

Frrat, B.,1998. Bitki Nasıl Beslenir, Atlas Kitapevi, Konya. 
Han, Z., Liu, G., Rao, Q.X., Bai, B., Zhao, Z.H., Liu, H., Wu, A.B., 2012. A liquid chromatography tandem mass spectrometry method for simultaneous determination of acid/alkaline phytohormones in grapes. J. Chromatogr. B, 881/882: 83. doi: 10.1016/j.jchromb.2011.12.002

Hu J.Y., Li, J.Z., 2006. Determination of Forchlorfenuron Residues in Watermelon by Solid-Phase Extraction and High-Performance Liquid Chromatography J. AOAC Int., 89: 1635. doi:10.1093/jaoac/89.6.1635

Kaynak, L., Ersoy, N., 1997. Bitki büyüme düzenleyicilerinin genel özellikleri ve kullanım alanları, Akd. Üniv. Zir. Fak. Dergisi, 10: 223-236.

Koukourikou-Petridou, M.A., 1996. Paclobutrazol affects growth of almond fruits andgermination of almond seeds. Plant Growth Reg., 20: 267-269.

Kumlay, A.M., Eryiğit, T. 2011. Bitkilerde Büyüme ve Gelişmeyi Düzenleyici Maddeler: Bitki Hormonları. Iğdır Üni. Fen Bilimleri Enst. Der. 1(2): 47-56.

Li L, Tian S.L., 2007. ELISA Analysis on the ABA content of jinmai leaves. J Anhui Agri. Sci. 35(23) : 7098- 7099.

Lehotay, S. J. 2007 Determination of Pesticide Residues in Foods by Acetonitrile Extraction and Partitioning with Magnesium Sulfate: Collaborative Study. J. AOAC Int. 2007, 90, 485-520.

Liu, S. Wu, Y., Fang, C., Cui, Y., Jiang, N., Wang, H. 2017. Simultaneous Determination of 19 Plant Growth Regulator Residues in Plant-originated Foods by QuEChERS and Stable Isotope Dilution-Ultra Performance Liquid Chromatography-Mass Spectrometry, Analytical Sciences, 33 (9): 1047-1052. doi:10.2116/analsci.33.1047

Liu, B.F., Zhong, X.H., Lu, Y.T., 2002. Analysis of plant hormones in tobacco flowers by micellar electrokinetic capillary chromatography coupled wit on-line large volüme sample stacking J. Chromatogr. A, 945: 257. doi:10.1016/s0021-9673(01)01503-5

López-Carbonell, M., Gabasa, M., Jáuregui, O., 2009. Enhanced determination of abscisic acid (ABA) and abscisic acid glucose ester (ABA-GE) in Cistus albidus plants by liquid chromatography-mass spectrometry in tandem mode. Plant Physiol. Bioch., 47: 256. doi: 10.1016/j.plaphy.2008.12.016

Nartvaranant, P., Subhadrabandhu, S., Tongumpai, P., 2000. Practical aspects in producing off-season mango in Thailand. Acta Horticulturae, 509, 661-668. doi:10.17660/ActaHortic.2000.509.75

Nickell, L. G., 1979. "Plant Growth Substances", American Chemical Society.

Pan, X., Welti, R., Wang, X., 2008. Simultaneous quantification of major phytohormones and related compounds in crude plant extracts by liquid chromatography-electrospray tandem mass spectrometry. Phytochemistry, 69: 1773. doi:10.1016/j.phytochem.2008.02.008

Pantaleón, C. S., Mercader, J. V., Agulloc, C., Abad- Somovilla, A., Abad-Fuentes, A. 2010. Hapten Synthesis and Polyclonal Antibody-Based Immunoassay Development for the Analysis of Forchlorfenuron in Kiwifruit.. Journal of Agricultural and Food Chemistry, 58 (15): 8502-8511. doi:10.1021/jf101660z

Pektaş, İ., 2009. Bitki Gelişim Düzenleyicilerin Antioksidan Enzimler Üzerindeki Etkisinin Araştırılması. Balıkesir Üniversitesi, Yüksek Lisans Tezi.73s, Balıkesir.

Polat, B., Tiryaki, O. 2019. Determination of some pesticide residues in conventional-grown and IPM-grown tomato by using QuEChERS method, Journal of Environmental Science and Health, Part B, 54(2), 112-117.

$\mathrm{Pu}, \mathrm{C}-\mathrm{H} .$, Lin, S-K., Chuang, W-C. ve Shyu, T-H., 2018. Modified QuEChERS method for 24 plant growth regulators in grapes using LC-MS/MS, Journal of Food and Drug Analysis, 26: (2) 637-648. doi:10.1016/j.jfda.2017.08.001

SANCO, 2011. Method validation and quality control procedures for pesticide residues analysis in food and feed. SANCO/12495/2011

SANTE, 2017. Guidance document on analytical quality control and method validation procedures for pesticides residues a nalysis in food and feed. SANTE/11813/2017.

Sørensen M.T., Danielsen V., 2006. Effects of the plant growth regulator, chlormequat, on mammalian fertility. Int J Androl, 29(1):129-133. doi:10.1111/j.1365-2605.2005.00629.x

Valverde, A., Piedra, L., Aguilera, A., Boulaid, M., Camacho, F., 2007. Analysis and residue levels of forchlorfenuron (CPPU) in watermelons.J. Environ. Sci. Health Part B, 42(7): 801. doi:10.1080/03601230701551475

Yan, Z., Nie, J., Xu, G., Li, H., Li, J., Li, Z., Wu,Y., Kuang, L., 2016, Simultaneous Determination of Plant Growth Regulators in Fruits Using a Modified QuEChERS Procedure and UPLC-MS/MS, Horticultural Plant Journal, 2(4): 203-208. doi:10.1016/j.hpj.2016.07.002

Yılmaz, H.R., Yüksel, E., 2002a. İndol 3 Asetik Asitin 3. Nesil Farelerin Kemik İliği Hücrelerinde Mitotik İn-deks Üzerine Etkisi, S.D.Ü Tıp Fakültesi Dergisi, 12(2): 46-49.

Yılmaz, H.R., Yüksel E., 2002b. 2,4-D Herbisitinin İleri Jenerasyonlarda Fare Böbrek Enzimleri Üzerine Etkisi, Firat Tip Dergisi, 7(3): 818-822.

Yılmaz, H.R., Yüksel, E., Türköz, Y., 2014. "F2 Nesil Farelerde Indol-3-Asetik Asitin Böbrek Katalaz, Süperoksit Dismutaz ve Glutatyon Peroksidaz Aktiviteleri Üzerine Olan Etkisi”, Van Tip Dergisi, 11(3):64-68. 
Zhang, F.Z., Zhao, P.Y., Shan, W.L., Gong, Y., Jian, Q., Pan, C.P., 2012. Development of a Method for the Analysis of Four Plant Growth Regulators (PGRs) Residues in Soybean Sprouts and Mung Bean Sprouts by Liquid Chromatography-Tandem Mass Spectrometry. Bull. Environ. Cont. Toxicol., 89: 674-679. doi:10.1007/s00128012-0739-z

Walsh, C.S., 2003. Plant Hormones. Concise Encyclopedia of Temperate Tree Fruit. Haworth Press. 245- 250.

Wu, P.G., Tan, Y., Zhang, J., Wang, L.Y., Tang, J., Jiang, W., Pan, X.D., Ma, B.J., Ni, Z.N., Wang, T.J., 2014. Determination of 10 plant growth regulators in bean sprouts by sequential cleaning-gas chromatography-mass spectrometry. Chinese J. Anal. Chem., 42(6): 866-871. doi:10.3724/SP.J.1096.2014.40105 